\title{
Organometallic-Based Hybrid Perovskite Piezoelectrics with a Narrow Band
}

Gap

Zhi-Xu Zhang, ${ }^{\dagger}$ Han-Yue Zhang, , ${ }^{* \dagger}$ Wei Zhang,,${ }^{\S}$ Xiao-Gang Chen, ${ }^{\dagger}$ Hui Wang, ${ }^{,}$and Ren-Gen Xiong ${ }^{*}, \dagger$

†Jiangsu Key Laboratory for Science and Applications of Molecular Ferroelectrics, Southeast University, Nanjing 211189, People's Republic of China

${ }^{\star}$ School of Physics and Engineering, Henan University of Science and Technology, Luoyang 471023, People’s Republic of China

${ }^{\S}$ Shanghai Institute of Applied Physics, Chinese Academy of Sciences, Shanghai 201800, People’s Republic of China 


\section{Methods}

Single-crystal X-ray crystallography. Single-crystal X-ray diffraction data of (FMTMA)PbI 3 , (FMTMA) $\mathrm{PbBr}_{2} \mathrm{I}$ and (FMTMA) $\mathrm{PbCl}_{2} \mathrm{I}$ at $293 \mathrm{~K}$ were measured using a Rigaku Saturn 924 diffractometer with Mo-K $\alpha$ radiation $(\lambda=0.71073 \AA)$. Data collection, cell refinement, and data reduction was performed using Rigaku CrystalClear 1.3.5. The structures were solved by direct methods and refined by the full-matrix method based on $F^{2}$ using the SHELXTL software package. All non-hydrogen atoms were refined anisotropically and the positions of all hydrogen atoms were generated geometrically. The data collection and structure refinement of these crystals are summarized in Table S1.

Powder X-ray diffraction. Powder X-ray diffraction (PXRD) data were measured using a Rigaku D/MAX 2000 PC X-ray diffraction system with $\mathrm{Cu} \mathrm{K} \alpha$ radiation in the $2 \theta$ range of $5^{\circ}-50^{\circ}$ with a step size of $0.02^{\circ}$.

SHG and dielectric measurements. An unexpanded laser beam with low divergence (pulsed $\mathrm{Nd}$ :YAG at a wavelength of $1064 \mathrm{~nm}, 5 \mathrm{~ns}$ pulse duration, $1.6 \mathrm{MW}$ peak power, $10 \mathrm{~Hz}$ repetition rate) was used to perform the second harmonic generation (SHG) experiments. The instrument model is Ins 1210058, INSTEC Instruments, while the laser is Vibrant 355 II, OPOTEK. Complex dielectric permittivities were measured with a TH2828A impedance analyzer. The samples were made with pressed-powder pellet for dielectric measurements. Silver conductive paste deposited on the plate surfaces of samples were used as top and bottom electrodes.

Hirshfeld surfaces analysis. Molecular Hirshfeld surface and the related 2D-fingerprint plot calculations were performed by using the CrystalExplorer17.5 program with inputting structure file in CIF format. All bond lengths to hydrogen were automatically modified to typical standard neutron values. In this work, all the Hirshfeld surfaces were generated using a standard (high) surface resolution. The intensity of molecular interaction is mapped onto the Hirshfeld surface by using a redblue-white color scheme: where the white regions exactly correspond to the distance of van der Waals 
contact, the blue regions correspond to longer contacts, and the red regions represent closer contacts. In 2D fingerprint plots, each point represents an individual pair $\left(d_{\mathrm{i}}, d_{\mathrm{e}}\right)$, reflecting the distances to the nearest atom inside $\left(d_{\mathrm{i}}\right)$ and outside $\left(d_{\mathrm{e}}\right)$ of the Hirshfeld surface, and the frequency of occurrence for these points corresponds to the colors from blue (low), through green, to red (highest).

Ultraviolet-Visible (UV-Vis) Spectra. Ultraviolet-visible (UV-vis) diffuse reflectance spectroscopy of (FMTMA) $\mathrm{PbCl}_{2} \mathrm{I}$, (FMTMA) $\mathrm{PbBr}_{2} \mathrm{I}$ and (FMTMA) $\mathrm{PbI}_{3}$ were measured on polycrystalline samples by using Shimadzu (Tokyo, Japan) UV-2600 spectrophotometer in the range of 200-800 nm at room temperature. The optical band gap $(E \mathrm{~g})$ of these materials were estimated from Tauc equation:

$$
\left[h v \cdot F\left(R_{\infty}\right)\right]^{1 / n}=\mathrm{A}(h v-E g)
$$

where $h$ is Planck constant, $v$ is the frequency of vibration, $\mathrm{A}$ is the proportional constant, $\mathrm{F}\left(\mathrm{R}_{\infty}\right)$ is the Kubelka-Munk function, and $n$ represents the nature of the sample's transition, $n=1 / 2$ for direct and $\mathrm{n}=2$ for indirect transition. The $E_{\mathrm{g}}$ can be obtained from a Tauc plot by plotting $\left[\mathrm{hv} \cdot \mathrm{F}\left(\mathrm{R}_{\infty}\right)\right]^{1 / \mathrm{n}}$ against the energy in electron volt.

Theoretical Calculation. The electronic band structures and partial density of states of (FMTMA) $\mathrm{PbCl}_{2} \mathrm{I}$, (FMTMA) $\mathrm{PbBr}_{2} \mathrm{I}$ and (FMTMA) $\mathrm{PbI}_{3}$ were performed based on density functional theory (DFT) by using the CASTEP module in the Materials Studio software (Accelrys, San Diego, CA, USA). Perdew-Burke-Ernzerhof was used to deal with the exchange and correlation effects in the generalized gradient approximation. The core-electron interactions were described by the normconserving pseudo-potential. The energy cutoff and the convergence threshold were set to $600 \mathrm{eV}$ and $10^{-6} \mathrm{eV}$ per atom, respectively. In addition, the other parameters and convergent criteria were the default values of CASTP module code. 

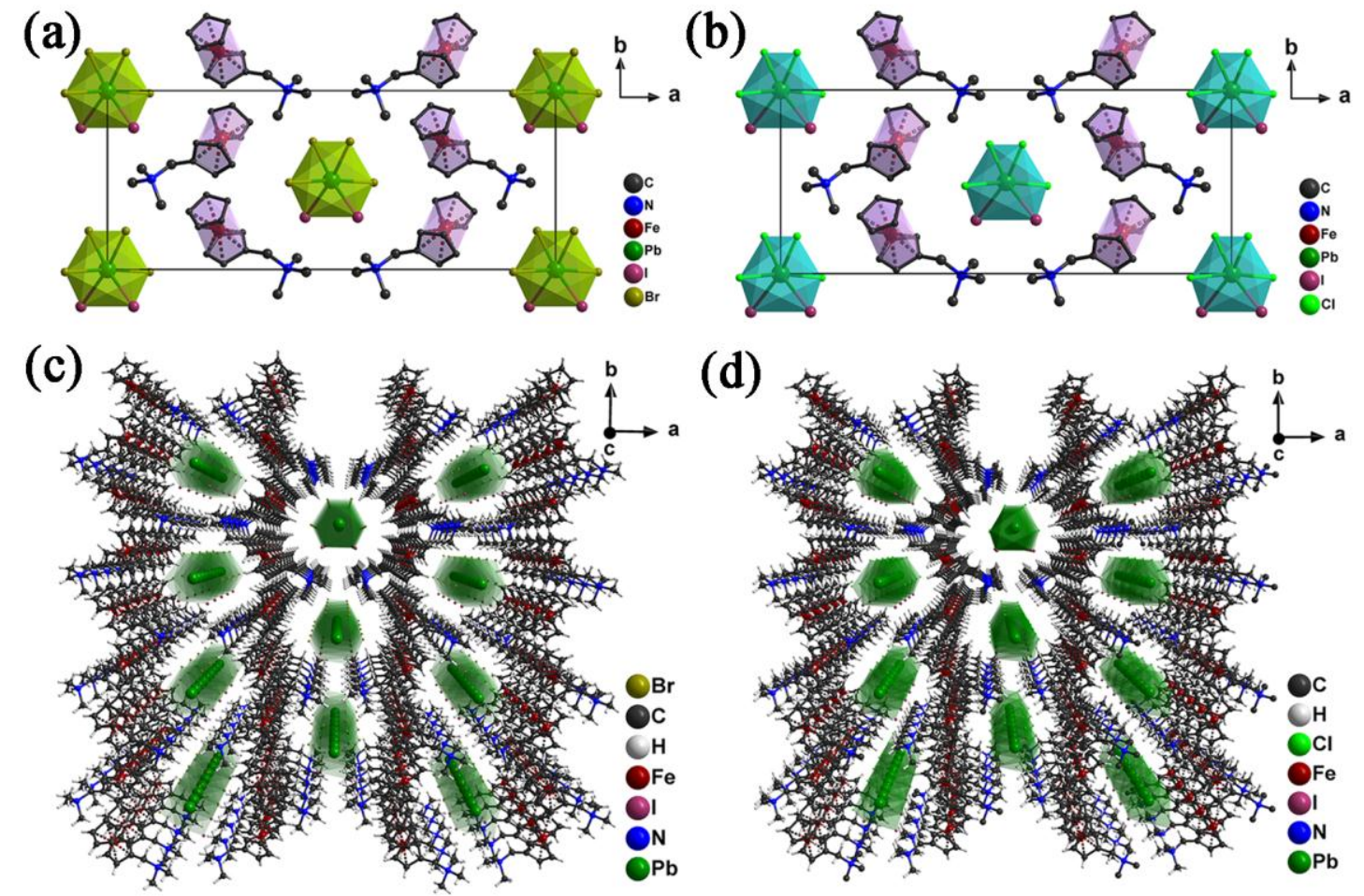

Figure S1. The packing view of structure along $c$-axis from parallel viewing angle for (a) (FMTMA) $\mathrm{PbBr}_{2} \mathrm{I}$ and (b) (FMTMA) $\mathrm{PbCl}_{2} \mathrm{I}$. The packing view of structure along $c$-axis from central viewing angle for (c) (FMTMA) $\mathrm{PbBr}_{2} \mathrm{I}$ and (d) (FMTMA) $\mathrm{PbCl}_{2} \mathrm{I}$.

(a)

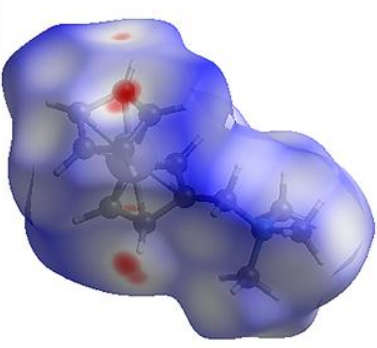

(b)

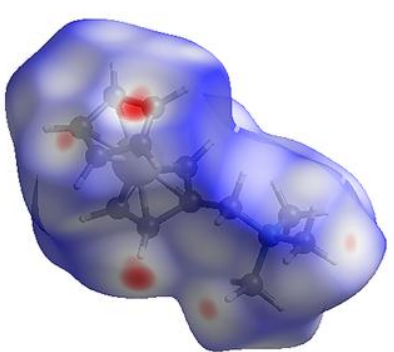

(c)

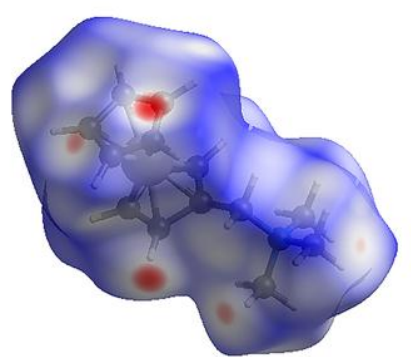

Figure S2. Hirshfeld $d_{\text {norm }}$ surfaces of $\left(\right.$ FMTMA) ${ }^{+}$cations in (a) (FMTMA) $\mathrm{PbI}_{3}$, (b) (FMTMA) $\mathrm{PbBr}_{2} \mathrm{I}$ and (c) (FMTMA) $\mathrm{PbCl}_{2} \mathrm{I}$, respectively. 

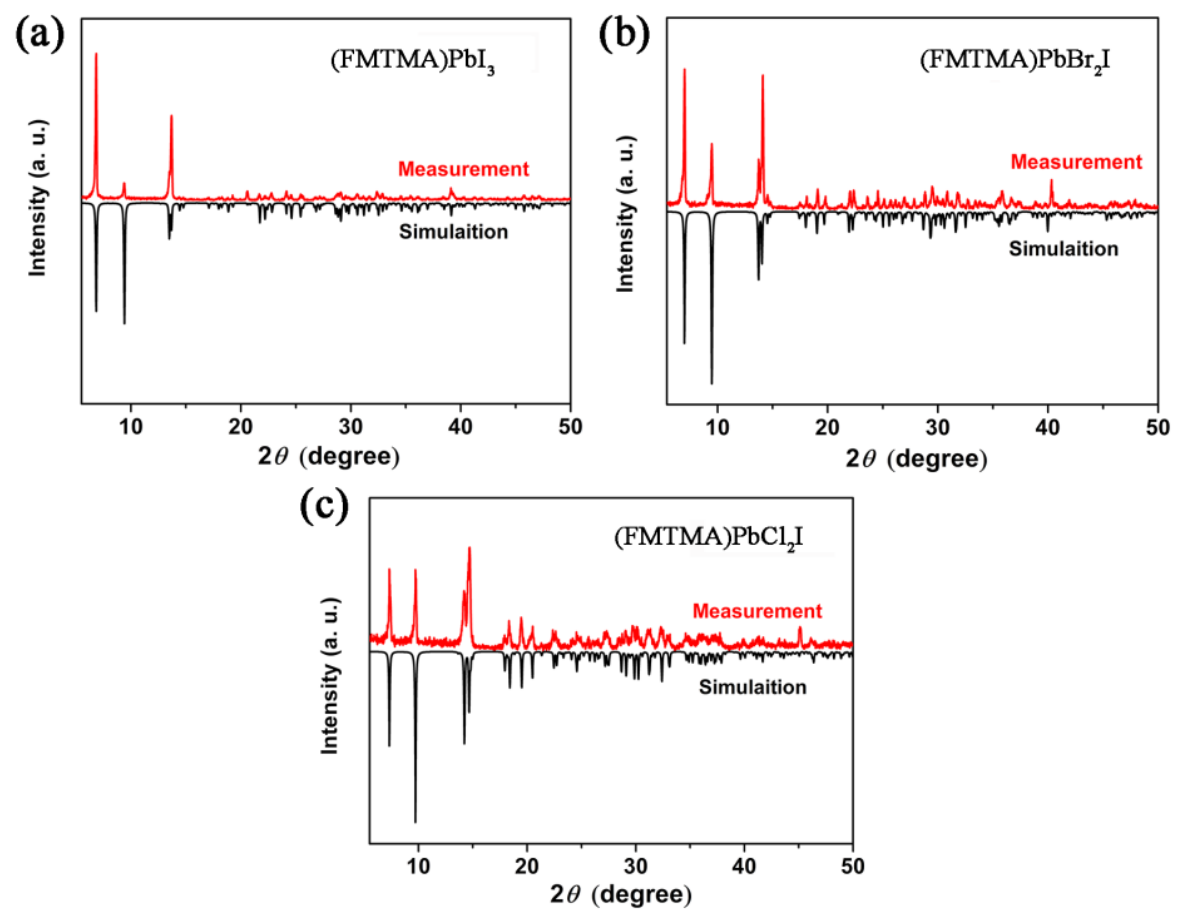

Figure S3. Patterns of the powder X-rays diffraction (PXRD) of (a) (FMTMA)PbI $\mathrm{F}_{3}$ (b) (FMTMA) $\mathrm{PbBr}_{2} \mathrm{I}$ and (c) (FMTMA) $\mathrm{PbCl}_{2} \mathrm{I}$ at $293 \mathrm{~K}$ match well with the simulated ones, verifying the purity of the bulk phase.

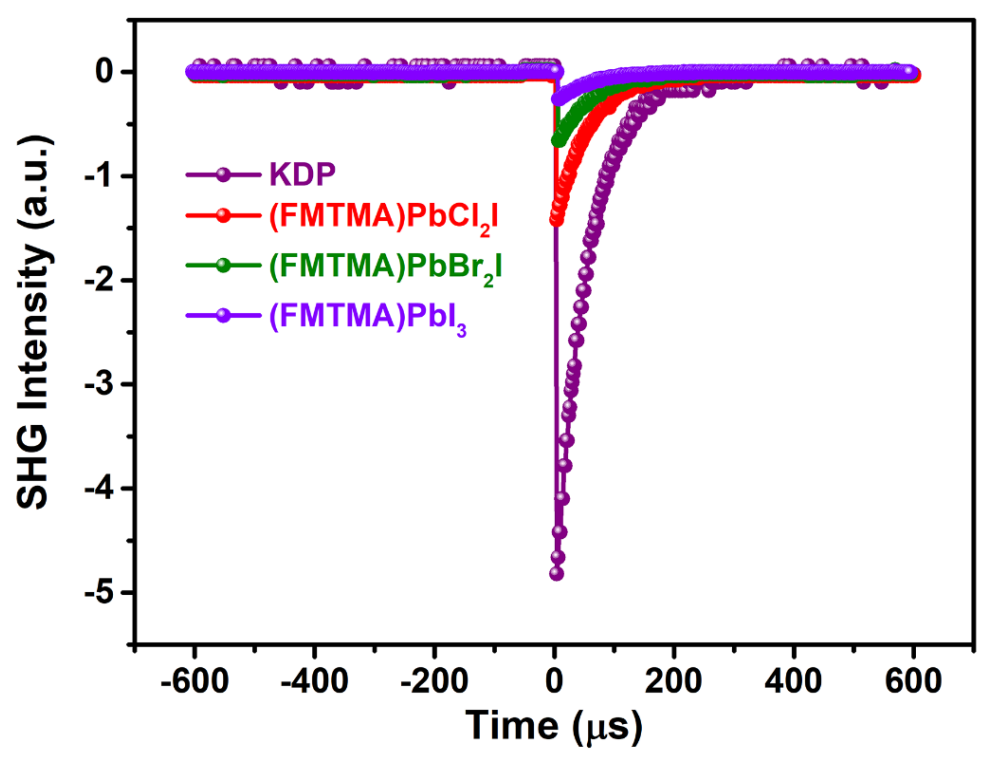

Figure S4. Comparison of SHG intensity for (FMTMA) $\mathrm{PbI}_{3}$, (FMTMA) $\mathrm{PbBr}_{2} \mathrm{I}$, (FMTMA) $\mathrm{PbCl}_{2} \mathrm{I}$, and KDP. 
(a)

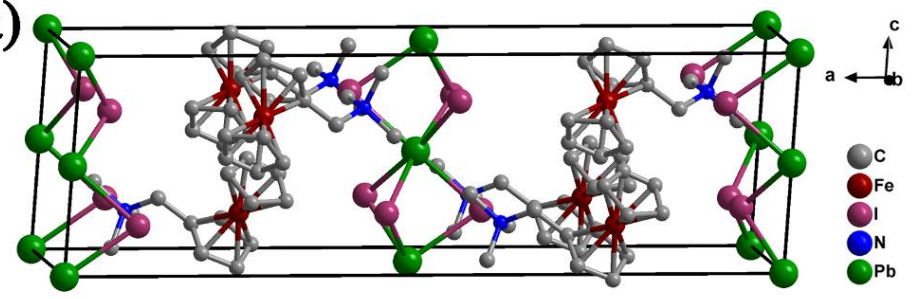

(b)

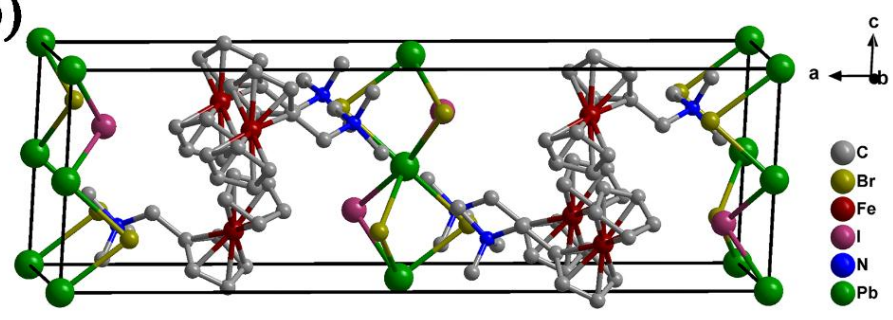

(c)

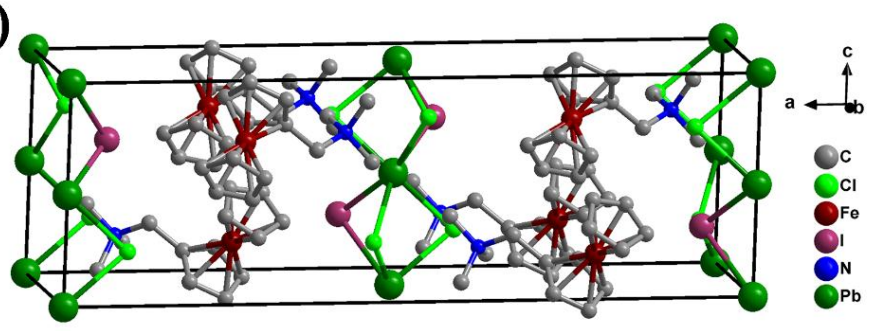

Figure S5. Distribution of $\mathrm{N}, \mathrm{Pb}$ and $\mathrm{X}(\mathrm{X}=\mathrm{Cl}, \mathrm{Br}, \mathrm{I})$ atoms in the unit cell at $293 \mathrm{~K}$ of (a) (FMTMA) $\mathrm{PbI}_{3}$, (b) (FMTMA) $\mathrm{PbBr}_{2} \mathrm{I}$ and (c) (FMTMA) $\mathrm{PbCl}_{2} \mathrm{I}$, respectively.

\section{Calculations based on the point charge models}

According to the crystal structure data collected at $293 \mathrm{~K}$, we select a unit cell and assume that the center of positive charge locates on the $\mathrm{N}$ and $\mathrm{Pb}$ atoms, and negative charge on the $\mathrm{X}(\mathrm{X}=\mathrm{Cl}, \mathrm{Br}, \mathrm{I})$ atoms, respectively (Figure S5).

\section{(FMTMA)PbI3}

\begin{tabular}{|c|c|}
\hline Atom & Center coordination \\
\hline $\mathrm{N}^{+}(4)$ & $(0.5,0.04071,0.5)$ \\
\hline $\mathrm{Pb}^{2+}(4)$ & $(0.5,0.0344,0.5)$ \\
\hline $\mathrm{I}^{-}(12)$ & $(0.5,0.03645,0.5)$ \\
\hline
\end{tabular}


$P_{s}=\lim \frac{1}{V} \sum q_{i} r_{i}$

$=\left(q_{\mathrm{N}} r_{\mathrm{N}}+q_{\mathrm{Pb}} r_{\mathrm{Pb}}+q_{\mathrm{I}} r_{\mathrm{I}}\right) / \mathrm{V}$

$=(0.04071 \times 4+0.0344 \times 8-0.03645 \times 12) \times 1.6 \times 10^{-19} \times 10.0928 \times 10^{-10} /\left(2071.70 \times 10^{-30}\right)$

$=0.005 \times 10^{-2} \mathrm{C} \mathrm{m}^{-2}$

$\left|P_{s}\right|=0.005 \times 10^{-2} \mathrm{C} \mathrm{m}^{-2}=0.005 \mu \mathrm{C} \mathrm{cm}^{-2}$

Dipole moment: $|\mu|=\left|q_{\mathrm{N}} r_{\mathrm{N}}+q_{\mathrm{Pb}} r_{\mathrm{Pb}}+q_{\mathrm{I}} r_{\mathrm{I}}\right|=0.0103 \times 10^{-29} \mathrm{C} \mathrm{m}$

(FMTMA)PbBr2I

\begin{tabular}{|c|c|}
\hline Atom & Center coordination \\
\hline $\mathrm{N}^{+}(4)$ & $(0.5,-0.01,0.5)$ \\
\hline $\mathrm{Pb}^{2+}(4)$ & $(0.5,-0.0159,0.5)$ \\
\hline $\mathrm{X}^{-}(12)$ & $(0.5,-0.01762,0.5)$ \\
\hline
\end{tabular}

$P_{s}=\lim \frac{1}{V} \sum q_{i} r_{i}$

$=\left(q_{\mathrm{N}} r_{\mathrm{N}}+q_{\mathrm{Pb}} r_{\mathrm{Pb}}+q_{\mathrm{X}} r_{\mathrm{X}}\right) / \mathrm{V}$

$=(-0.01 \times 4-0.0159 \times 8+0.01762 \times 12) \times 1.6 \times 10^{-19} \times 10.0268 \times 10^{-10} /\left(2006.80 \times 10^{-30}\right)$

$=0.354 \times 10^{-2} \mathrm{C} \mathrm{m}^{-2}$

$\left|P_{s}\right|=0.354 \times 10^{-2} \mathrm{C} \mathrm{m}^{-2}=0.354 \mu \mathrm{C} \mathrm{cm}^{-2}$

Dipole moment: $|\mu|=\left|q_{\mathrm{N}} r_{\mathrm{N}}+q_{\mathrm{Pb}} r_{\mathrm{Pb}}+q_{\mathrm{X}} r_{\mathrm{X}}\right|=0.7097 \times 10^{-29} \mathrm{C} \mathrm{m}$ 
(FMTMA) $\mathrm{PbCl}_{2} \mathbf{I}$

\begin{tabular}{|c|c|}
\hline Atom & Center coordination \\
\hline $\mathrm{N}^{+}(4)$ & $(0.5,-0.0238,0.5)$ \\
\hline $\mathrm{Pb}^{2+}(4)$ & $(0.5,-0.01406,0.5)$ \\
\hline $\mathrm{X}^{-}(12)$ & $(0.5,-0.02235,0.5)$ \\
\hline
\end{tabular}

$P_{s}=\lim \frac{1}{V} \sum q_{i} r_{i}$

$=\left(q_{\mathrm{N}} r_{\mathrm{N}}+q_{\mathrm{Pb}} r_{\mathrm{Pb}}+q_{\mathrm{X}} r_{\mathrm{X}}\right) / \mathrm{V}$

$=(-0.0238 \times 4-0.01406 \times 8+0.02235 \times 12) \times 1.6 \times 10^{-19} \times 9.8138 \times 10^{-10} /\left(1858.81 \times 10^{-30}\right)$

$=0.511 \times 10^{-2} \mathrm{C} \mathrm{m}^{-2}$

$\left|P_{s}\right|=0.511 \times 10^{-2} \mathrm{C} \mathrm{m}^{-2}=0.511 \mu \mathrm{C} \mathrm{cm}^{-2}$

Dipole moment: $|\mu|=\left|q_{\mathrm{N}} r_{\mathrm{N}}+q_{\mathrm{Pb}} r_{\mathrm{Pb}}+q_{\mathrm{X}} r_{\mathrm{X}}\right|=0.9503 \times 10^{-29} \mathrm{C} \mathrm{m}$ 

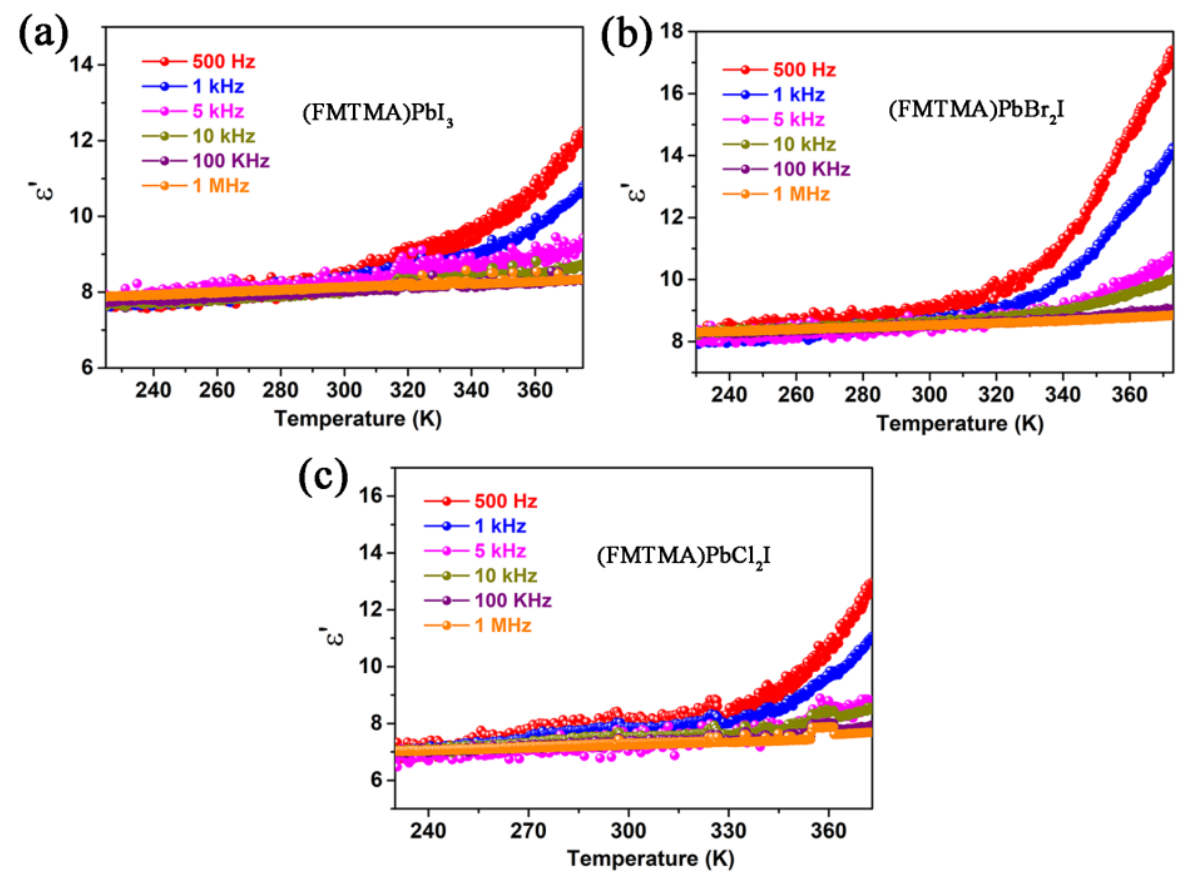

Figure S6. Temperature dependence of the real part of complex dielectric permittivity for polycrystalline samples of (a) (FMTMA) $\mathrm{PbI}_{3}$, (b) (FMTMA) $\mathrm{PbBr}_{2} \mathrm{I}$ and (c) (FMTMA) $\mathrm{PbCl}_{2} \mathrm{I}$.

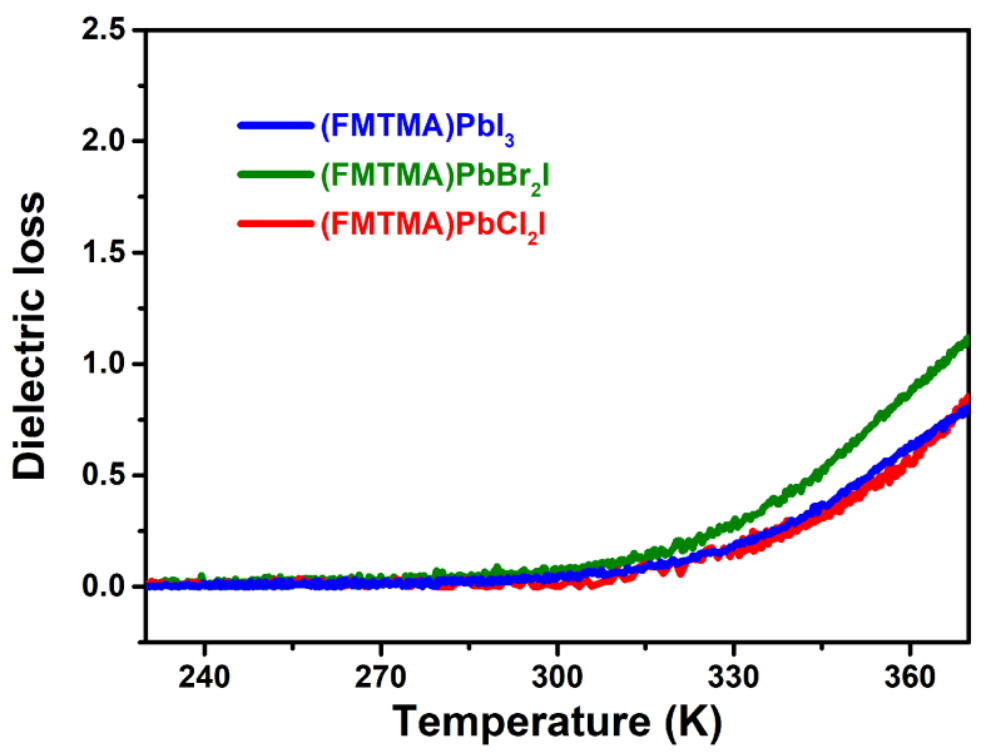

Figure S7. Dielectric loss for polycrystalline samples of (a) (FMTMA) $\mathrm{PbI}_{3}$, (b) (FMTMA) $\mathrm{PbBr}_{2} \mathrm{I}$ and (c) (FMTMA) $\mathrm{PbCl}_{2} \mathrm{I}$, respectively. 

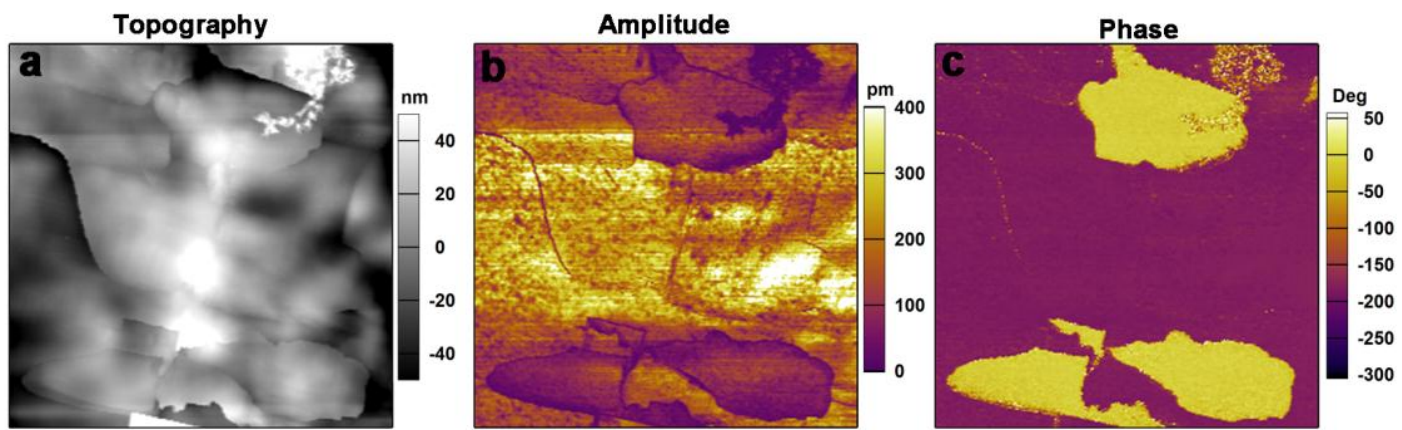

Figure S8. (a) Surface topographic image, PFM (b) amplitude and (c) phase images for the thin film of (FMTMA)PbI .
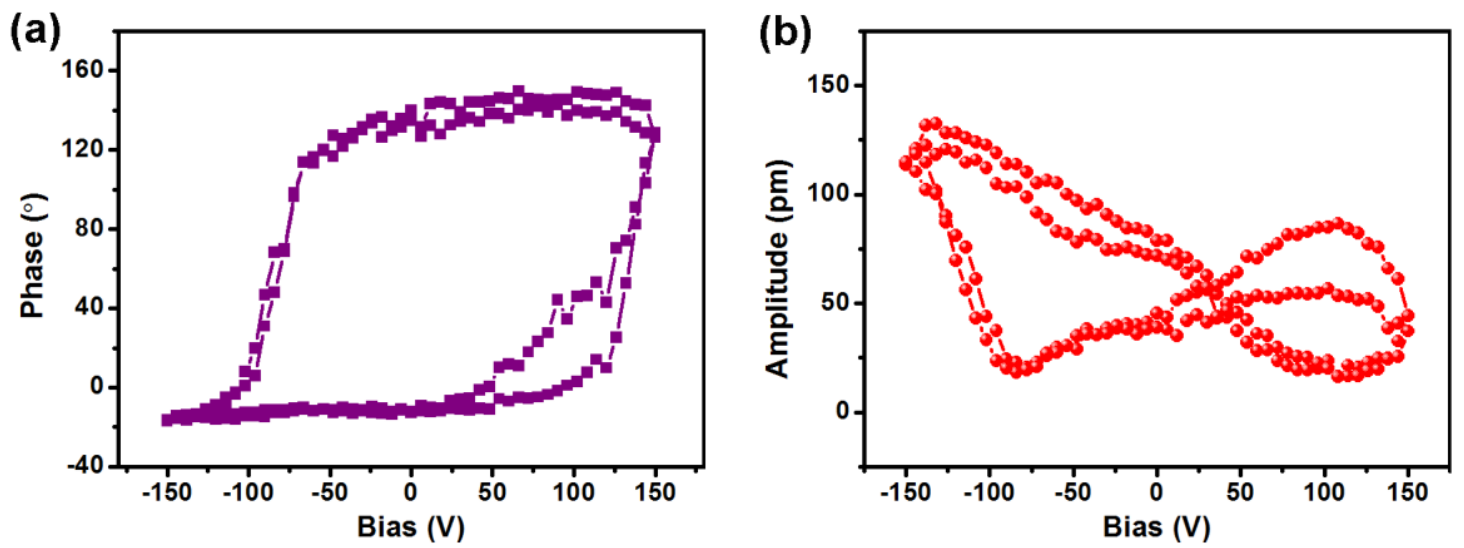

Figure S9. Switching spectroscopy PFM measurements for the (FMTMA) $\mathrm{PbI}_{3}$ thin film, further confirming its ferroelectricity. A set of dc voltages up to $\pm 150 \mathrm{~V}$ in triangle sawtooth form were applied to the sample to switch its polarization. Simultaneously, a $2 \mathrm{~V}$ ac voltage was applied to measure the corresponding amplitude and phase signals. It is found that the phase loops show a square shape and the $180^{\circ}$ shift occurs when a coercive voltage is exceeded, approximately $-84 \mathrm{~V}$ on the negative side and $+113 \mathrm{~V}$ on the positive side (a). Accompanied with the phase reversal, typical amplitude-voltage butterfly loops are also observed (b). 


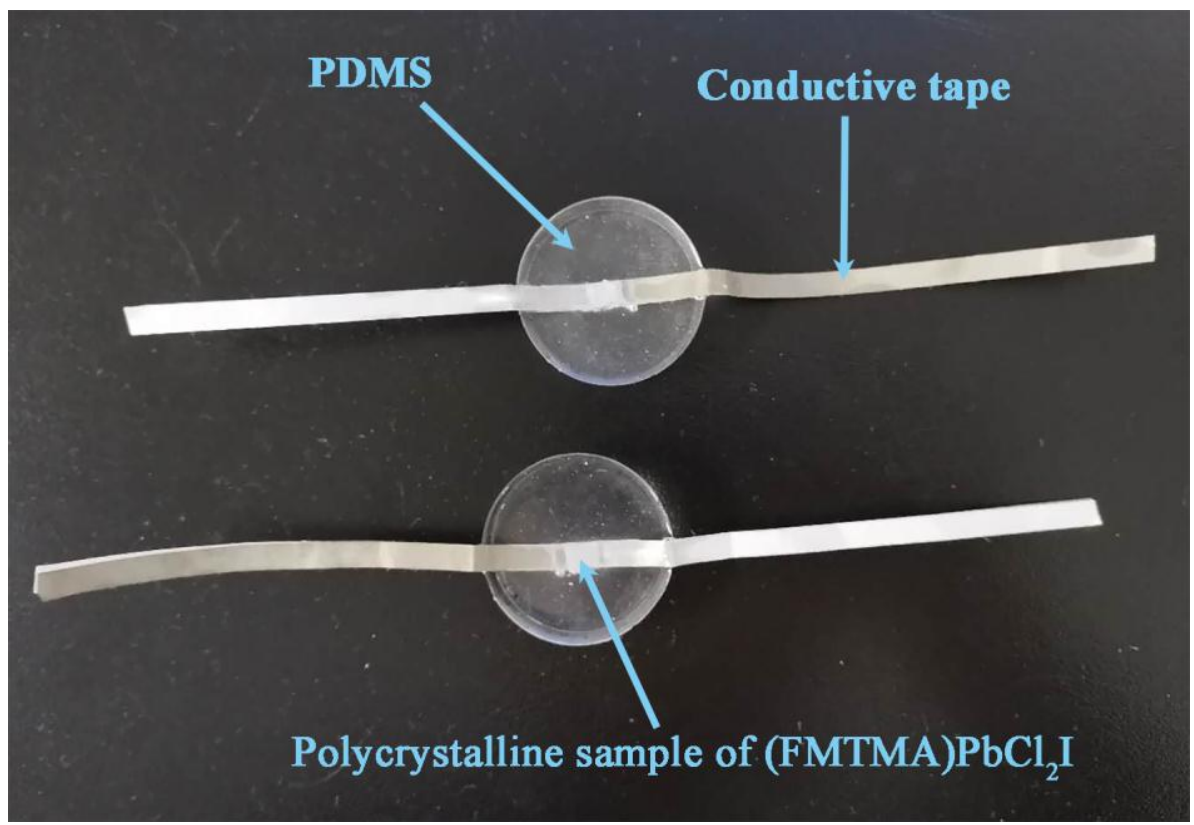

Figure S10. The photo of piezoelectric energy harvesting component based on (FMTMA) $\mathrm{PbCl}_{2} \mathrm{I}$.
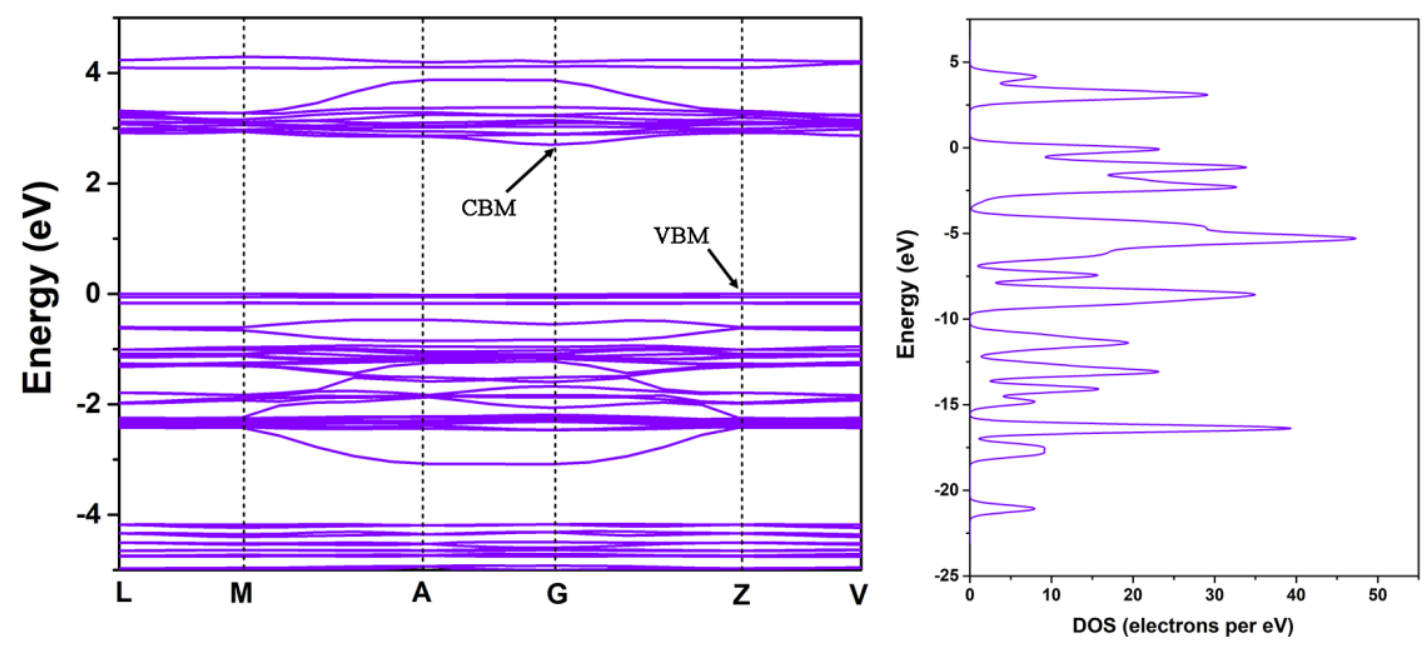

Figure S11. Energy band structure and density of states (DOS) of (FMTMA) $\mathrm{PbI}_{3}$. The conduction band minimum (CBM) and the valence band maximum (VBM) are localized at different points in the Brillouin zone, suggesting the indirect band gap nature. 


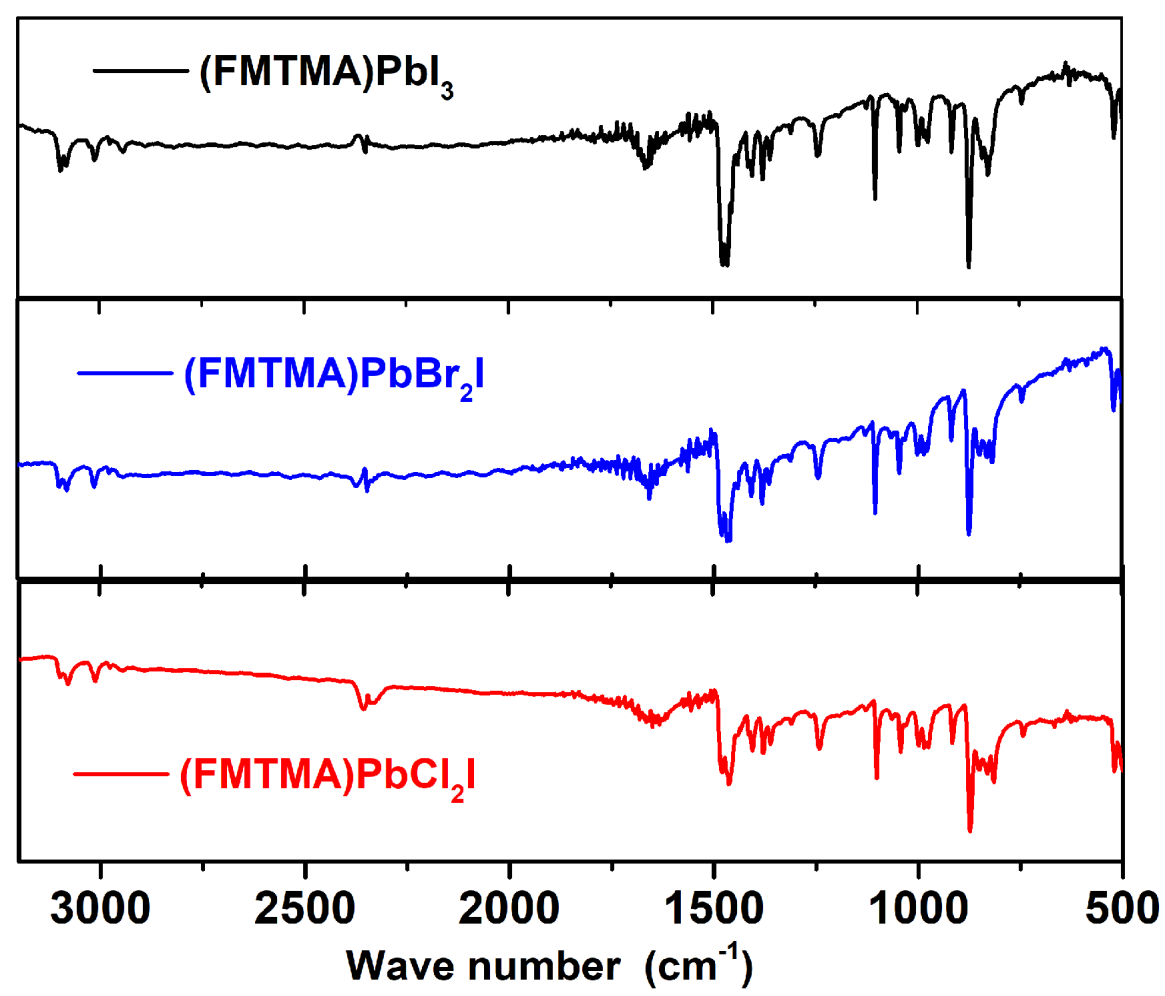

Figure S12. Infrared (IR) spectrum of (FMTMA) $\mathrm{PbI}_{3}$, (FMTMA) $\mathrm{PbBr}_{2} \mathrm{I}$ and (FMTMA) $\mathrm{PbCl}_{2} \mathrm{I}$, respectively.

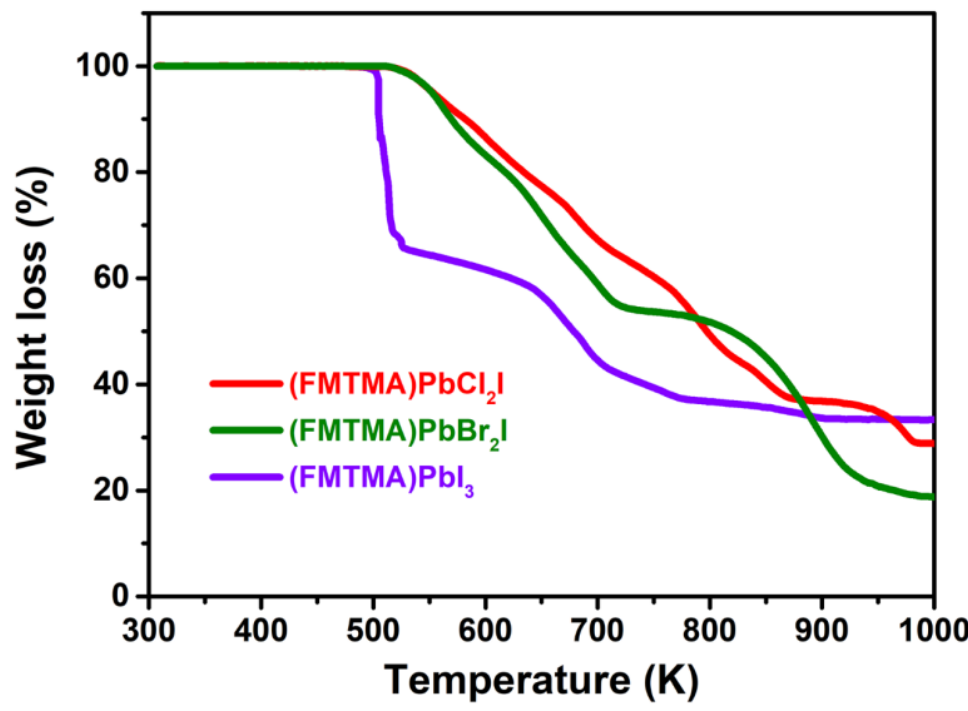

Figure S13. Thermogravimetric analysis of (FMTMA) $\mathrm{PbI}_{3}$, (FMTMA) $\mathrm{PbBr}_{2} \mathrm{I}$, and (FMTMA) $\mathrm{PbCl}_{2} \mathrm{I}$, showing the good thermal stability up to about 493, 512, and $515 \mathrm{~K}$, respectively. 
Table S1. Crystal data and structure refinement for (FMTMA) $\mathrm{PbI}_{3}$, (FMTMA) $\mathrm{PbBr}_{2} \mathrm{I}$ and (FMTMA) $\mathrm{PbCl}_{2} \mathrm{I}$ at $293 \mathrm{~K}$, respectively.

\begin{tabular}{|c|c|c|c|}
\hline Compound & (FMTMA) $\mathrm{PbI}_{3}$ & (FMTMA)PbBr 2 I & (FMTMA)PbCl \\
\hline Temperature & $293 \mathrm{~K}$ & $293 \mathrm{~K}$ & $293 \mathrm{~K}$ \\
\hline Formula & $\mathrm{C}_{14} \mathrm{H}_{20} \mathrm{NFePbI}_{3}$ & $\mathrm{C}_{14} \mathrm{H}_{20} \mathrm{NFePbBr} \mathrm{I}_{2}$ & $\mathrm{C}_{14} \mathrm{H}_{20} \mathrm{NFePbCl}_{2} \mathrm{I}$ \\
\hline $\mathrm{Mr}$ & 846.06 & 752.06 & 663.16 \\
\hline Crystal system & monoclinic & monoclinic & monoclinic \\
\hline Space group & $C 2$ & $C 2$ & $C 2$ \\
\hline \multirow[t]{3}{*}{$a, b, c(\AA)$} & $25.8959(16)$ & $25.2480(3)$ & $24.1460(10)$ \\
\hline & $10.0928(5)$ & $10.0268(7)$ & $9.8138(4)$ \\
\hline & $7.9440(4)$ & 7.9347(7) & $7.8489(3)$ \\
\hline$\beta\left({ }^{\circ}\right)$ & $93.798(5)$ & $92.550(9)$ & $91.965(4)$ \\
\hline$V\left(\AA^{3}\right)$ & $2071.70(19)$ & $2006.8(3)$ & $1858.81(13)$ \\
\hline$Z$ & 4 & 4 & 4 \\
\hline$R_{1}$ & 0.0611 & 0.0468 & 0.0357 \\
\hline $\mathrm{w} R_{2}$ & 0.1764 & 0.1341 & 0.1035 \\
\hline GOF & 1.099 & 1.128 & 1.102 \\
\hline
\end{tabular}

Table S2. Experimental and calculated lattice parameters.

\begin{tabular}{|c|c|c|c|c|c|}
\hline Material & & $a(\AA)$ & $b(\AA)$ & $c(\AA)$ & $\beta\left(\left(^{\circ}\right)\right.$ \\
\hline \multirow[t]{2}{*}{ (FMTMA) $\mathrm{PbCl}_{2} \mathrm{I}$} & Exp. & 24.15 & 9.81 & 7.85 & 91.97 \\
\hline & Cal. & 24.09 & 9.92 & 7.79 & 92.18 \\
\hline \multirow[t]{2}{*}{ (FMTMA) $\mathrm{PbBr}_{2} \mathrm{I}$} & Exp. & 25.25 & 10.03 & 7.93 & 92.55 \\
\hline & Cal. & 25.06 & 10.09 & 7.95 & 92.34 \\
\hline \multirow[t]{2}{*}{ (FMTMA) $\mathrm{PbI}_{3}$} & Exp. & 25.90 & 10.09 & 7.94 & 93.80 \\
\hline & Cal. & 25.62 & 10.14 & 8.00 & 93.70 \\
\hline
\end{tabular}

